Check for updates

Cite this: RSC Adv., 2019, 9, 23764

\title{
Structural versatility of the quasi-aromatic Möbius type zinc(II)-pseudohalide complexes - experimental and theoretical investigations $\uparrow$
}

\author{
Mariusz P. Mitoraj, (D) *a Farhad Akbari Afkhami, (D) ${ }^{\mathrm{b}}$ Ghodrat Mahmoudi, (D) *c

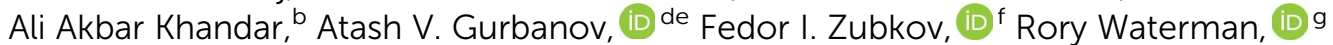 \\ Maria G. Babashkina, ${ }^{\text {h }}$ Dariusz W. Szczepanik, (D) ${ }^{a}$ Himanshu S. Jena (D) \\ and Damir A. Safin (D)*h
}

In this contribution we report for the first time fabrication, isolation, structural and theoretical characterization of the quasi-aromatic Möbius complexes [Zn(NCS) $\left.L^{\prime}\right]$ (1), $\left[Z_{2}\left(\mu_{1,1}-N_{3}\right)_{2}\left(L^{\prime}\right)_{2}\right]$ $\left[\mathrm{ZnCl}_{3}(\mathrm{MeOH})\right]_{2} \cdot 6 \mathrm{MeOH}$ (2) and $\left[\mathrm{Zn}(\mathrm{NCS}) L^{\prime \prime}\right]_{2}\left[\mathrm{Zn}(\mathrm{NCS})_{4}\right] \cdot \mathrm{MeOH}$ (3), constructed from 1,2-diphenyl-1,2bis((phenyl(pyridin-2-yl)methylene)hydrazono)ethane $\quad\left(L^{\prime}\right)$ or benzilbis(acetylpyridin-2-yl) methylidenehydrazone (L"), respectively, and $\mathrm{ZnCl}_{2}$ mixed with $\mathrm{NH}_{4} \mathrm{NCS}$ or $\mathrm{NaN}_{3}$. Structures 1-3 are dictated by both the bulkiness of the organic ligand and the nature of the inorganic counter ion. As evidenced from single crystal X-ray diffraction data species 1 has a neutral discrete heteroleptic mononuclear structure, whereas, complexes 2 and 3 exhibit a salt-like structure. Each structure contains a $\mathrm{Zn}$ " atom chelated by one tetradentate twisted ligand $L^{\prime}$ creating the unusual Möbius type topology. Theoretical investigations based on the EDDB method allowed us to determine that it constitutes the quasi-aromatic Möbius motif where a metal only induces the $\pi$-delocalization solely within the ligand part: $2.44|e|$ in $3,3.14|e|$ in 2 and $3.44|e|$ in 1 . It is found, that the degree of quasi-aromatic $\pi$ delocalization in the case of zinc species is significantly weaker (by $\sim 50 \%$ ) than the corresponding estimations for cadmium systems - it is associated with the $\mathrm{Zn}-\mathrm{N}$ bonds being more polar than the related $\mathrm{Cd}-\mathrm{N}$ connections. The ETS-NOCV showed, that the monomers in 1 are bonded primarily through London dispersion forces, whereas long-range electrostatic stabilization is crucial in 2 and 3 . A number of non-covalent interactions are additionally identified in the lattices of 1-3.

Received 10th July 2019 Accepted 24th July 2019 DOI: $10.1039 / c 9 r a 05276 c$

rsc.li/rsc-advances

\section{Introduction}

${ }^{a}$ Department of Theoretical Chemistry, Faculty of Chemistry, Jagiellonian University, Gronostajowa 2, 30-387 Cracow, Poland. E-mail:mitoraj@chemia.uj.edu.pl ${ }^{b}$ Department of Inorganic Chemistry, Faculty of Chemistry, University of Tabriz, 51666-16471, Tabriz, Iran

'Department of Chemistry, Faculty of Science, University of Maragheh, P.O. Box 5518183111, Maragheh, Iran.E-mail: mahmoudi_ghodrat@yahoo.co.uk

${ }^{d}$ Department of Chemistry, Baku State University, Z. Xalilov Str. 23, AZ1148, Baku, Azerbaijan

${ }^{e}$ Centro de Quimica Estrutural, Instituto Superior Técnico, Universidade de Lisboa, Av. Rovisco Pais, 1049-001, Lisboa, Portugal

${ }^{f}$ Organic Chemistry Department, Faculty of Science, Peoples' Friendship University of Russia (RUDN University), 6 Miklukho-Maklaya St., Moscow, 117198, Russian Federation

${ }^{8}$ Department of Chemistry, University of Vermont, 82 University Place, Burlington, VT 05405, USA

'Institute of Chemistry, University of Tyumen, Perekopskaya Str. 15a, 625003 Tyumen, Russian Federation.E-mail: damir.a.safin@gmail.com; d.a.safin@utmn.ru

${ }^{i}$ COMOC, Department of Chemistry, Ghent University, Krijgslaan 281-S3B, Ghent9000, Belgium

† Electronic supplementary information (ESI) available: Fig. S1-S4, Tables S1-S4 and cif files. CCDC 1901201-1901203 For ESI and crystallographic data in CIF or other electronic format see DOI: 10.1039/c9ra05276c
Helical molecules are highly favoured by nature. ${ }^{1}$ Such molecules are of great importance, which is also supported by the structure of deoxyribonucleic acid first discovered in $1953 .^{2}$

On the other hand, zinc(II) ( $\mathrm{Zn}^{\mathrm{II}}$ ) ions are found in all six main classes of metalloenzymes and are essential for living organisms. ${ }^{3,4}$ Moreover, the dinuclear $\mathrm{Zn}^{\mathrm{II}}$ complex fabricated from doubly deprotonated octaethyl formylbiliverdine is the first established helical doublestranded structure, which was reported in $1976 .{ }^{5}$ Following this discovery, strategies towards helical structure as well as their self-assembly have been the focus of researchers. ${ }^{6,7}$ Obviously, the most powerful strategy towards metal-based helical structures is the smart predesign of parent ligands. The other strategy, which, however, is less predictable and thus less efficient, is the choice of a metalcontaining precursor. The latter is much less investigated. ${ }^{5-7}$

Some efforts have been focused on the design and preparation of helical metal complexes by applying chelating ligands with suitable donor sites. ${ }^{7-16}$ The point is that the ligand should produce a helical topology upon binding to the metal ions. In 
some cases, the coordination features of the cations dictate the wrapping of non-helical chelating ligands around them in such a manner that they can be twisted and eventually form helical complexes. ${ }^{7,9-11,13,15}$ However, synthesis of organic ligands with a helical topology is more difficult than metallo-organic compounds and there are only a few reported synthetic helical organic molecules. ${ }^{\mathbf{8 1 2 , 1 4 , 1 6 , 1 7}}$ Researchers mainly focused on the design and construction of metal complexes with synthetic helical chelating ligands. ${ }^{\mathbf{1 8 - 2 0}}$ Recently, we have also directed our attention to Schiff bases comprising two pyridyl-imine functions obtained from benzyldihydrazone. ${ }^{21-27}$ These ligands were found to be efficient for helical structures upon coordination to metal centers. Particularly our comprehensive efforts were directed to various $\mathrm{Cd}^{\mathrm{II}}$ salts as complexing agents. ${ }^{23-27}$ Moreover, we were able to demonstrate for the first time that the helical motif in the obtained complexes together with the chelate metalloring correspond to a quasi-aromatic Möbius object. $^{24,27}$

Herein, we report $\mathrm{Zn}(\mathrm{NCS})_{2}$ - and $\mathrm{Zn}\left(\mathrm{N}_{3}\right)_{2}$-derived structures with 1,2-diphenyl-1,2-bis((phenyl(pyridin-2-yl)methylene) hydrazono)ethane (L $\left.\mathbf{L}^{\mathbf{I}}\right)$ and benzilbis(acetylpyridin-2-yl) methylidenehydrazone $\left(\mathbf{L}^{\mathbf{I I}}\right)$. Using thiocyanate $\left(\mathrm{NCS}^{-}\right)$and azide $\left(\mathrm{N}_{3}{ }^{-}\right)$counterions is intriguing and of great interest since both anions are known to be ambidentate ligands, which can bind metal centers in different coordination modes. ${ }^{28,29}$ As a result were able to isolate the unique quasi-aromatic Möbius type zinc complexes $\left[\mathrm{Zn}(\mathrm{NCS})_{2} \mathrm{~L}^{\mathrm{I}}\right] \quad(\mathbf{1}), \quad\left[\mathrm{Zn}_{2}\left(\mu_{1,1}-\mathrm{N}_{3}\right)_{2}\left(\mathrm{~L}^{\mathrm{I}}\right)_{2}\right]$ $\left[\mathrm{ZnCl}_{3}(\mathrm{MeOH})\right]_{2} \cdot 6 \mathrm{MeOH} \quad(2)$ and $\left[\mathrm{Zn}(\mathrm{NCS}) \mathrm{L}^{\mathrm{II}}\right]_{2}\left[\mathrm{Zn}(\mathrm{NCS})_{4}\right]$. $\mathrm{MeOH}$ (3), respectively. Notably, our numerous attempts to isolate crystals of the reaction product of $\mathrm{Zn}\left(\mathrm{N}_{3}\right)_{2}$ and $\mathbf{L}^{\mathbf{I}}$ failed regardless using a great number of $\mathrm{Zn}^{\mathrm{II}}$ and $\mathrm{N}_{3}{ }^{-}$sources. DFT experiments were additionally performed to estimate the stability and aromaticity of the obtained species.

\section{Results and discussion}

Interaction of $\mathrm{ZnCl}_{2}$ mixed with $\mathrm{NH}_{4} \mathrm{NCS}$ or $\mathrm{NaN}_{3}$ with $\mathbf{L}^{\mathbf{I}}$ or $\mathbf{L}^{\mathbf{I I}}$ in $\mathrm{MeOH}$ at $60^{\circ} \mathrm{C}$ has allowed to isolate complexes 1-3 (Scheme 1 and ESI $\dagger$ ). The elemental analysis data supports their compositions. Notably, the same one-pot reaction of $\mathbf{L}^{\mathbf{I}}$ or $\mathbf{L}^{\mathbf{I I}}$ with $\mathrm{Cd}\left(\mathrm{NO}_{3}\right)_{2}$ in the presence of $\mathrm{NH}_{4} \mathrm{NCS}$ produced a dinuclear structure $\left[\mathrm{Cd}_{2}\left(\mu_{1,3}-\mathrm{NCS}\right)_{2}(\mathrm{NCS})_{2}\left(\mathrm{~L}^{\mathrm{III}}\right)_{2}\right] \cdot 4 \mathrm{MeOH}(4)$, where $\mathbf{L}^{\mathrm{III}}$ is formed upon hydrolysis of one of the 2-PyC $(\mathrm{Ph})$ functions of $\mathbf{L}^{\mathbf{I}},^{27}$ and neutral mononuclear complex $\left[\mathrm{Cd}(\mathrm{NCS})_{2}\left(\mathrm{~L}^{\mathrm{II}}\right)(\mathrm{MeOH})\right]$ (5), ${ }^{24}$ respectively.

The FTIR spectrum of 1 contains a characteristic intense band at $2073 \mathrm{~cm}^{-1}$ attributed to the $\mathrm{CN}$ stretching of $\mathrm{NCS}^{-}$. The same stretching mode in the IR spectrum of 3 is shown as two clearly defined bands at 2066 and $2112 \mathrm{~cm}^{-1}$, corresponding to two different types of the $\mathrm{NCS}^{-}$ligands (Scheme 1). These bands are in the typical region for the N-linked terminal $\mathrm{NCS}^{-}$ions. $^{30}$ The $\mathrm{N}_{3}{ }^{-}$anions in the FTIR spectrum of 2 are shown as an intense band at $2054 \mathrm{~cm}^{-1}$ arising from the $\nu_{\text {asym }}$ stretching vibration, as well as a band at $1441 \mathrm{~cm}^{-1}$ corresponding to the $\nu_{\text {asym }}$ stretching vibration. The $\mathrm{C}=\mathrm{N}$ stretching vibration is at a lower energy by $40 \mathrm{~cm}^{-1}$ for complexes 1 and 2 compared to the free ligand $\mathbf{L}^{\mathbf{I}}$, whilst a similar $20 \mathrm{~cm}^{-1}$ difference is observed in this vibration between compound 3 and $\mathbf{L}^{\text {II }} .^{22}$ This firmly confirms the participation of the azomethine nitrogen atoms in chelate formation. The FTIR spectra of 2 and 3 further contain a broad band for the methanol at 3353 to $3443 \mathrm{~cm}^{-1}$, respectively.

Complex 1 crystallizes in the monoclinic space group $P 2_{1} / n$, while complexes 2 and 3 each crystallize in the triclinic space group $P \overline{1}$. It is worthy to note, that $\mathbf{1}$ is isostructural to its $\mathrm{Mn}^{\mathrm{II}}$ and $\mathrm{Co}^{\mathrm{II}}$ analogues. ${ }^{22,31}$

Complex 1 has a neutral discrete heteroleptic mononuclear structure, where the $\mathrm{Zn}^{\mathrm{II}}$ metal center is coordinated by one ligand $\mathbf{L}^{\mathbf{I}}$ via its two pyridyl-imine chelate functions as well as two $\mathrm{N}$-bound $\mathrm{NCS}^{-}$anions giving rise to the $\mathrm{ZnN}_{6}$ chromophore with a distorted trigonal-prismatic coordination environment around the cation (Fig. 1, Table S1 in the ESI $\dagger$ ), which has been proven by the SHAPE 2.1 software. ${ }^{32,33}$

Complexes 2 and 3 each exhibit a salt-like structure (Scheme 1), as opposed to our previously studied $\mathrm{Cd}^{\mathrm{II}}$ based counterparts. ${ }^{23-27}$ In 2 , the cationic part exhibits a doubly charged centrosymmetric dinuclear structure, were two $\mathrm{Zn}^{\mathrm{II}}$ centers are interlinked via two $\mu_{1,1}-\mathrm{N}_{3}{ }^{-}$anions and the coordination domain of each metal is filled by the tetracoordinated ligand $\mathbf{L}^{\mathbf{I}}$ (Fig. 2). Here a coordination geometry is best described as a distorted octahedron (Table S1 in the ESI $\dagger$ ). ${ }^{32,33}$ The anionic part represents a discrete mononuclear structure of the composition $\left[\mathbf{Z n C l}_{\mathbf{3}}(\mathbf{M e O H})\right]^{-}$with a tetracoordinate $\mathrm{Cl}_{3} \mathrm{O}$ environment around the metal atom (Fig. 2). As evidenced from the so-called distortion index $\tau_{4}=0.9513,{ }^{34}$ the coordination core of $\left[\mathbf{Z n C l}_{3}(\mathbf{M e O H})\right]^{-}$is almost a perfect tetrahedron. This is also supported by the SHAPE 2.1 software (Table S1 in the $\mathrm{ESI} \dagger){ }^{32,35}$

The anionic part of 2 via one of its chlorine atoms and the methanol $\mathrm{OH}$ hydrogen atom is engaged in intermolecular hydrogen bonds with the lattice $\mathrm{MeOH}$ molecules yielding a synthon of motif $R_{8}^{8}(20)$ of the $\left(\left[\mathrm{ZnCl}_{3}(\mathrm{MeOH})\right]_{2}\right)^{2-} \cdot 6 \mathrm{MeOH}$ composition (Fig. 2, Table S2 in the ESI $\dagger$ ).

The salt like structure of 3 is built from two $\left[\mathbf{Z n}(\mathbf{N C S}) \mathbf{L}^{\mathbf{I I}}\right]^{+}$ cations, where the $\mathrm{Zn}^{\mathrm{II}}$ metal center is, similar to $\mathbf{1}$ and $\mathbf{2}$, chelated by two pyridyl-imine fragments of one parent ligand $\mathbf{L}^{\text {II }}$, and further bound by one N-linked $\mathrm{NCS}^{-}$anion, exhibiting a pentacoordinated geometry (Fig. 3). The distortion index $\tau_{5}{ }^{34}$ is 0.693 and 0.653 for two [ $\left.\mathbf{Z n}(\mathbf{N C S}) \mathbf{L}^{\text {II }}\right]^{+}$cations. These values are best described as being about $31 \%$ and $35 \%$, respectively, along the pathway of distortion from the ideal trigonal bipyramidal structure towards square pyramidal structure. The trigonal bipyramidal coordination environment is also evidenced from the SHAPE 2.1 software (Table S1 in the ESI $\dagger$ ). ${ }^{32,36}$

The anionic part of 3 exhibits a doubly charged [Zn(NCS $\left.)_{4}\right]^{2-}$ species, where four $\mathrm{NCS}^{-}$anions are bound via their $\mathrm{N}$-atoms yielding a tetracoordinated coordination geometry around the metal atom (Fig. 3). The $\tau_{4}$ value of 0.9594 indicates almost a perfect tetrahedron, which has also been supported by the SHAPE 2.1 software (Table S1 in the ESI†). ${ }^{32,35}$ Notably, the CS fragment of one of the $\mathrm{NCS}^{-}$anions is disordered over three positions with a ratio of $35 \%: 35 \%: 30 \%$ (Fig. 3).

The $\mathrm{Zn}-\mathrm{N}$ bonds in 1-3, formed by four nitrogen atoms of the corresponding organic ligands, are in the range from 


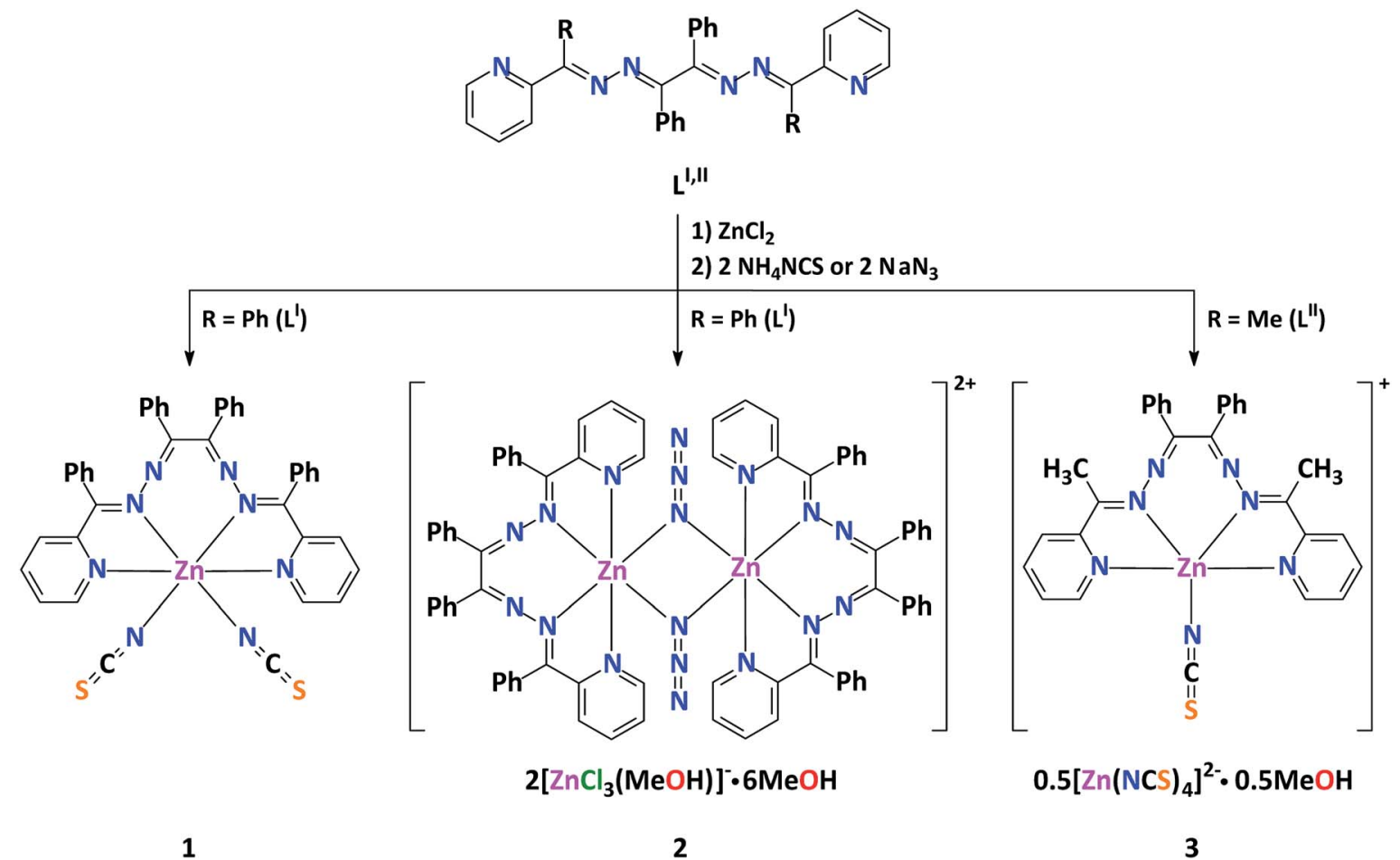

Scheme 1 Synthesis of complexes 1-3.

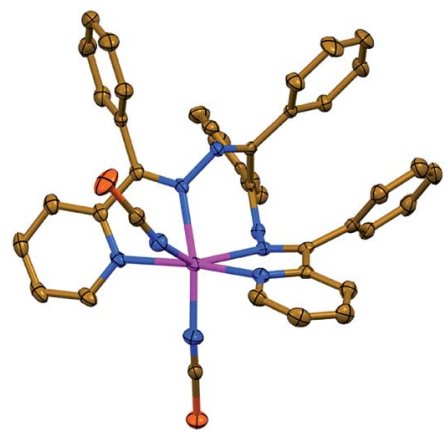

Fig. 1 Crystal structure of $1(\mathrm{H}$-hydrogen atoms are omitted for clarity). Color code: $\mathrm{C}=$ gold, $\mathrm{N}=$ blue, $\mathrm{S}=$ orange, $\mathrm{Zn}=$ magenta.

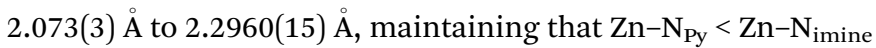
(Table 1). It is worthy to note, that the $\mathrm{Cd}(\mathrm{L})-\mathrm{NCS}$ bonds (1.970(3)-2.0289(18) $\AA$ ) in $\mathbf{1}$ and $\mathbf{3}$ are remarkably shorter than the $\mathrm{Zn}-\mathrm{N}_{\mathrm{Py}}$ and $\mathrm{Zn}-\mathrm{N}_{\text {imine }}$ bonds, while the $\mathrm{Zn}(\mathrm{L})-\mathrm{N}_{3}$ bonds in 2 are similar to those within the corresponding organic ligand. This is obviously explained by the terminal coordination mode of the $\mathrm{NCS}^{-}$anions in contrast to the $\mu_{1,1}$-coordination mode of $\mathrm{N}_{3}{ }^{-}$. The $\mathrm{Zn}-\mathrm{NCS}$ bonds within the $\left[\mathrm{Zn}(\mathbf{N C S})_{4}\right]^{2-}$ anion in 3 are 1.953(6)-1.983(4) $\AA$. All the $\mathrm{NCS}^{-}$and $\mathrm{N}_{3}{ }^{-}$ligands are almost linear (Table 1). The $\mathrm{Zn} \cdots \mathrm{Zn}$ separation within the dinuclear molecule of 2 is 3.3729(15) A.

Organic ligands in the structures of 1-3 each produce a twisted geometry of different extent. As a result of this conformation, the $\mathrm{N}-\mathrm{C}(\mathrm{Ph})-\mathrm{C}(\mathrm{Ph})-\mathrm{N}$ fragments adopt a torsion angle of about $65^{\circ}$ (Table 1), which is significantly lower than in
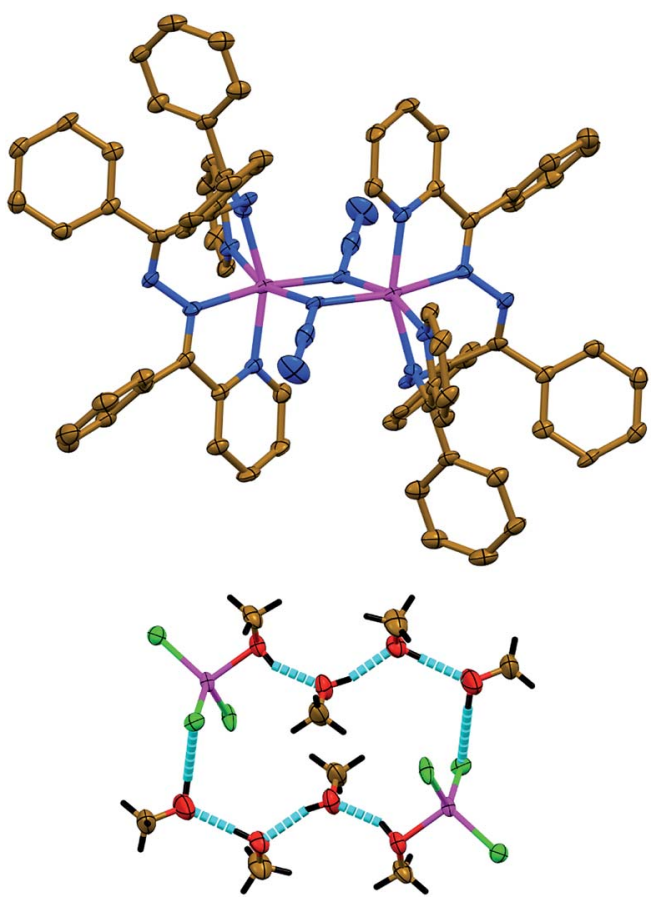

Fig. 2 (top) Crystal structure of the cationic part $\left[\mathrm{Zn}_{2}\left(\mu_{1,1}-\mathrm{N}_{3}\right)_{2}\left(\mathrm{~L}^{\prime}\right)_{2}\right]^{2+}$ of 2. Hydrogen atoms are omitted for clarity. Color code: $\mathrm{C}=$ gold, $\mathrm{N}$ $=$ blue, $\mathrm{Zn}=$ magenta. (bottom) Crystal structure of the hydrogen bonded synthon of motif $R_{8}^{8}(20)$ of the $\left(\left[\mathrm{ZnCl}_{3}(\mathrm{MeOH})\right]_{2}\right)^{2-} \cdot 6 \mathrm{MeOH}$ composition, constructed from the $\left[\mathrm{ZnCl}_{3}(\mathrm{MeOH})\right]^{-}$anionic part and lattice $\mathrm{MeOH}$ molecules of 2 . Color code: $\mathrm{H}=$ black, $\mathrm{C}=$ gold, $\mathrm{Cl}=$ green, $\mathrm{O}=$ red, $\mathrm{Zn}=$ magenta. 


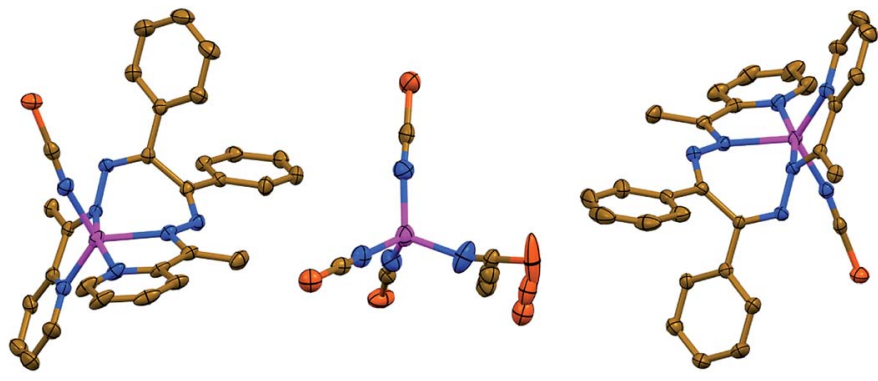

Fig. 3 Crystal structure of 3 (hydrogen atoms and $\mathrm{MeOH}$ molecules are omitted for clarity). Color code: $\mathrm{C}=$ gold, $\mathrm{N}=$ blue, $\mathrm{S}=$ orange, $\mathrm{Zn}=$ magenta.

the corresponding $\mathrm{Cd}^{\mathrm{II}}$ analogues. ${ }^{23-27}$ This is also reflected in the $\mathrm{Zn}-\mathrm{N}-\mathrm{N}-\mathrm{C}(\mathrm{Ph}), \mathrm{C}(\mathrm{Ph})-\mathrm{N}-\mathrm{N}-\mathrm{C}(\mathrm{Ph})$ in $\mathbf{1}$ and $\mathbf{2}$, and $\mathrm{C}(\mathrm{Me})-\mathrm{N}-$ $\mathrm{N}-\mathrm{C}(\mathrm{Ph})$ in 3 torsion angles. Particularly, a simultaneous influence of a pentacoordination mode of the metal center together with the presence of less bulkier Me substituents in complex 3 leads to the $\mathrm{C}(\mathrm{Me})-\mathrm{N}-\mathrm{N}-\mathrm{C}(\mathrm{Ph})$ torsion angles of close values $\left(\sim 138-153^{\circ}\right)$, while a hexacoordination mode of $\mathrm{Zn}^{\mathrm{II}}$ and the presence of the organic ligand, which is highly enriched by four phenyl fragments, induces significantly different $\mathrm{C}(\mathrm{Ph})-\mathrm{N}-$ $\mathrm{N}-\mathrm{C}(\mathrm{Ph})$ torsion angles within single species (Table 1 ). The $\mathrm{Zn}-$ $\mathrm{N}-\mathrm{N}-\mathrm{C}(\mathrm{Ph})$ torsion angles are very similar in $\mathbf{1}$, while the same angles in $\mathbf{2}$ and $\mathbf{3}$ are significantly different (Table 1). The torsion angle between two pyridyl rings ranges from about $51^{\circ}$ to $64^{\circ}$, increasing from 2 through 3 to 1 (Table 1 ).

Due to a twisted helical topology of organic ligands in the mononuclear structures of $\mathbf{1}$ and $\mathbf{3}$, enantiomers of the coordination species can be expected. Indeed, both structures exhibit molecules with $\Delta$ and $\Lambda$ helicity. The overall structure of $\mathbf{1}$ and $\mathbf{3}$ is a racemic mixture. The molecule of 2 , although also containing organic ligands with a twisted helical topology, is constructed from two chiral centres, resulting in the formation of the achiral meso-form.

Table 1 Selected bond lengths $(\AA)$ and angles $\left(^{\circ}\right)$ for $1-3$

$\begin{array}{lll}\text { Complex } 1 & \text { Complex } 2 & \text { Complex } 3\end{array}$

$2.2165(16), 2.2755(17)$

$2.2692(16), 2.2960(15)$

$2.0046(18), 2.0289(18)$

$-$

$\mathrm{Zn}(\mathrm{L})-\mathrm{NCS}$

$\mathrm{Zn}(\mathrm{L})-\mathrm{N}_{3}$

$\mathrm{Zn}-\mathrm{NCS}$

$\mathrm{Zn}(\mathrm{L}) \cdots \mathrm{Zn}(\mathrm{L})$

$-$

\section{Bond angles}

$\mathrm{N}_{\mathrm{Py}}-\mathrm{Zn}-\mathrm{N}_{\mathrm{Py}}$

$\mathrm{N}_{\mathrm{Py}}-\mathrm{Zn}-\mathrm{N}_{\text {imine }}$

$\mathrm{N}_{\text {imine }}-\mathrm{Zn}-\mathrm{N}_{\text {imine }}$

$\mathrm{N}_{\mathrm{Py}}-\mathrm{Zn}-\mathrm{NCS}$

$\mathrm{N}_{\text {imine }}-\mathrm{Zn}-\mathrm{NCS}$

$\mathrm{N}_{\mathrm{Py}}-\mathrm{Zn}-\mathrm{N}_{3}$

$\mathrm{N}_{\text {imine }}-\mathrm{Zn}-\mathrm{N}_{3}$

NCS-Zn(L)-NCS

NCS-Zn-NCS

$\mathrm{N}_{3}-\mathrm{Zn}-\mathrm{N}_{3}$

$\mathrm{Zn}(\mathrm{L})-\mathrm{N}-\mathrm{C}(\mathrm{S})$

$\mathrm{Zn}-\mathrm{N}-\mathrm{C}(\mathrm{S})$

$\mathrm{Zn}-\mathrm{N}-\mathrm{N}(\mathrm{N})$

$\mathrm{N}-\mathrm{C}-\mathrm{S}$

$\mathrm{N}-\mathrm{N}-\mathrm{N}$

$\mathrm{Zn}-\mathrm{N}-\mathrm{Zn}$

\section{Torsion angles ${ }^{a}$}

$\mathrm{N}-\mathrm{C}(\mathrm{Ph})-\mathrm{C}(\mathrm{Ph})-\mathrm{N}$

$\mathrm{C}(\mathrm{Ph})-\mathrm{N}-\mathrm{N}-\mathrm{C}(\mathrm{Ph})$

$\mathrm{C}(\mathrm{Me})-\mathrm{N}-\mathrm{N}-\mathrm{C}(\mathrm{Ph})$

$\mathrm{Py} \cdots \mathrm{Py}$

$\mathrm{Zn}-\mathrm{N}-\mathrm{N}-\mathrm{C}(\mathrm{Ph})$

\section{$170.55(6)$}

69.96(6), 70.63(6),

116.80(6), 118.40(6)

76.13(6)

86.22(7), 87.06(7),

87.39(6), 89.72(7)

88.08(6), 93.14(7),

142.43(6), 144.78(7)

-

117.54(7)

$-$

158.37(16), 156.48(18)

$-$

178.62(19), 178.9(2)

$-$

$-$
2.075(5), 2.168(5)

2.131(5), 2.265(5)

2.154(5), 2.225(4)

3.3729(15) (intramolecular)

103.76(17)

75.27(17), 75.95(17), 102.79(17),

$156.78(18)$

81.62(17)

$-$

$-$

89.25(17), 92.07(17), 98.01(18), 161.65(17)

89.89(17), 93.84(17), 105.15(17), 167.47(17)

-

$-$

79.26(17)

-

121.8(4), 123.4(4)

-

178.8(7)

$100.7(2)$
2.073(3), 2.079(4), 2.100(3)

2.107(3), 2.118(3), 2.119(3), 2.123(4)

1.970(3), 1.971(3)

-

1.953(6), 1.955(5), 1.971(5), 1.983(4)

$-$

104.50(14), 104.63(15)

76.44(12), 76.71(13), 78.20(14), 78.36(14),

119.93(12), 121.35(14), 163.40(13), 164.34(13)

86.81(12), 87.76(12)

97.89(14), 98.68(13), 122.76(15), 124.22(15)

94.12(13), 94.20(13), 114.07(15), 114.42(16)

-

, 105.3(2), 110.0(2), 112.00(17) $112.0(2), 112.73(17)$

165.7(4), 166.8(4)

149.5(11), 150.9(15), 158(3), 163.5(5), 169.6(4), 174.5(4)

$178.6(4), 179.2(4)$

$-$

66.1(6), 67.6(6)

138.5(4), 140.0(4), 152.4(4), 152.9(4)

$56.6(2), 58.0(2)$

$-47.0(5),-48.3(5),-71.2(3),-72.4(4)$

${ }^{a}$ Torsion angles must be compared by their magnitudes. 
The crystal packing of 1-3 is described by a network of faceto-face $\pi \cdots \pi$ stacking between the aromatic rings (Table S3 in the ESI $\dagger$ ). The structures of $\mathbf{1}$ and 2 are also dictated by $\mathrm{C}-\mathrm{H} \cdots \pi$ interactions (Table S4 in the ESI $\dagger$ ).

For more detailed analyses of non-covalent interactions in 13 the charge and energy decomposition scheme ETS-NOCV ${ }^{37}$ is applied as available in the ADF program. ${ }^{38}$ We have applied BLYP-D3/TZP since they provide reliable results for noncovalent interactions. ${ }^{39}$ The X-ray models are considered.

We have determined, that the neutral monomers of $\left[\mathrm{Zn}(\mathrm{NCS})_{2} \mathrm{~L}^{\mathrm{I}}\right]$ in $\mathbf{1}$ are efficiently bonded to each other with the interaction energy $\Delta E_{\text {int }}=-23.78 \mathrm{kcal} \mathrm{mol}^{-1}$ (Fig. 4). The main gluing force ( $55 \%$ of the overall stabilization) is the dispersion

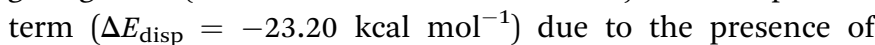
$\mathrm{C}-\mathrm{H} \cdots \mathrm{S}$ and $\mathrm{C}-\mathrm{H} \cdots \pi$ contacts (Fig. 4). Such close contacts enforce additionally less important electrostatic $\left(28.5 \%, \Delta E_{\text {elstat }}\right.$ $\left.=-12.01 \mathrm{kcal} \mathrm{mol}^{-1}\right)$ and charge delocalisation $\left(16.5 \%, \Delta E_{\mathrm{orb}}=\right.$ $-6.95 \mathrm{kcal} \mathrm{mol}^{-1}$ ) constituents (Fig. 4). The prevalence of the $\Delta E_{\text {disp }}$ term is consistent with recent findings, which rediscover the importance of London dispersion forces in small and size-

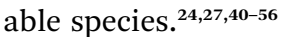

In 3 the $\left[\mathrm{Zn}(\mathrm{NCS})_{4}\right]^{2-}$ anion sticks very strongly $\left(\Delta E_{\mathrm{int}}=\right.$ $\left.-193.21 \mathrm{kcal} \mathrm{mol}^{-1}\right)$ to two neighboring stacked [Zn(NCS) $\left.\mathbf{L}^{\text {II }}\right]^{+}$ units primarily through electrostatic forces $(75.3 \%$ of the overall stabilization) (Fig. 5). Quite notable (14.8\%) is the charge delocalization term $\Delta E_{\text {orb }}=-31.10 \mathrm{kcal} \mathrm{mol}^{-1}$ mostly due to C$\mathrm{H} \cdots \pi$ contacts followed by the least important (9.90\%) dispersion term $\Delta E_{\text {disp }}=-20.62 \mathrm{kcal} \mathrm{mol}^{-1}$ (Fig. 5). It is interesting to emphasize, that such ionic bonds are of crucial importance for the overall stability of 3 since the pure $\pi \cdots \pi$ stacking between the $\left[\mathbf{Z n}(\mathbf{N C S}) \mathbf{L}^{\text {II }}\right]^{+}$units, though containing a significant portion of dispersion stabilization $\left(\Delta E_{\text {disp }}=-31.76 \mathrm{kcal} \mathrm{mol}^{-1}\right)$, is

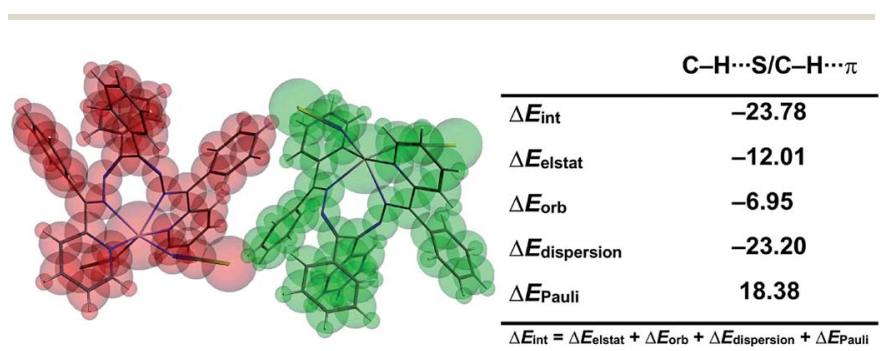

$\Delta \rho_{\text {orb }}$

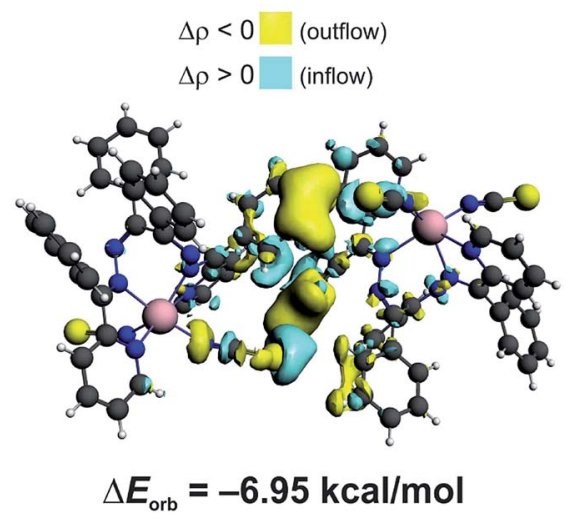

Fig. 4 (top) ETS-NOCV outcomes scrutinizing the nature of bonding between the $\left[\mathrm{Zn}(\mathrm{NCS})_{2} \mathrm{~L}^{\prime}\right]$ monomers in 1 . (bottom) The overall change in electron density $\Delta \rho_{\text {orb }}$ with the corresponding energy $\Delta E_{\text {orb. }}$. found to be repulsive with $\Delta E_{\text {int }}=7.86 \mathrm{kcal} \mathrm{mol}^{-1}$ caused predominantly by the unfavourable electrostatic constituent $\Delta E_{\text {elstat }}=29.1 \mathrm{kcal} \mathrm{mol}^{-1}$ (Fig. 6). In 2 the electrostatically dominated stabilizing interactions occur between $\left[\mathbf{Z n C l}_{\mathbf{3}}(-\right.$ $\mathbf{M e O H})]^{-}$and $\left[\mathbf{Z n}_{2}\left(\mu_{1,1}-\mathbf{N}_{3}\right)_{2}\left(\mathbf{L}^{\mathbf{I}}\right)_{2}\right]^{2+}$ (Fig. S1 in the ESI $\dagger$ ). Additionally, $\left[\mathrm{ZnCl}_{\mathbf{3}}(\mathbf{M e O H})\right]^{-}$forms primarily $\mathrm{O}-\mathrm{H} \cdots \mathrm{O}$ as well as a series of ancillary $\mathrm{C}-\mathrm{H} \cdots \mathrm{Cl}$ hydrogen bonds with the neighbouring methanol species. Such cooperative interactions, leading to $\Delta E_{\text {int }}=-13.17 \mathrm{kcal} \mathrm{mol}^{-1}$, are found to be determined mostly by the electrostatic factor $(50 \%)$ followed by the charge delocalization (27\%) and dispersion (23\%) constituents (Fig. S2 in the ESI $\dagger$ ). The synthon $\left[\mathbf{Z n}_{2}\left(\mu_{1,1}-\mathbf{N}_{3}\right)_{2}\left(\mathbf{L}^{\mathbf{I}}\right)_{2}\right]^{2+}$ was found to be stable due to electrostatically dominated $\left(\Delta E_{\text {elstat }}=\right.$ $-63.33 \mathrm{kcal} \mathrm{mol}^{-1}$ ) dative-covalent $\mathrm{Zn}-\mathrm{N}$ connections with $\Delta E_{\mathrm{int}}$ $=-31.63 \mathrm{kcal} \mathrm{mol}^{-1}$ constituted additionally from the significant portion of London dispersion forces $\left(\Delta E_{\mathrm{disp}}=\right.$ $-37.25 \mathrm{kcal} \mathrm{mol}^{-1}$ ) (Fig. S3 in the ESI $\dagger$ ).

In order to evaluate aromaticity in 1-3, we have applied the electron density of delocalized bonds (EDDB) method, which has been proposed to visualize and quantify aromaticity and chemical resonance in a wide range of chemical species. ${ }^{57-60}$

Moreover, it has recently been shown that, in the case of organometallics, the EDDB method provides very useful data on the role of the transition metal d-orbitals in electron delocalization, ${ }^{24,27,50,61}$ which is inaccessible by means of such popular and commonly used aromaticity descriptors as the nucleusindependent chemical shift (NICS) ${ }^{62}$ or the anisotropy of the induced current density (ACID). ${ }^{63}$

The global EDDB isocontours and the corresponding electron populations of 1-3 are collected in Fig. S4 in the ESI. $\dagger$ Here,

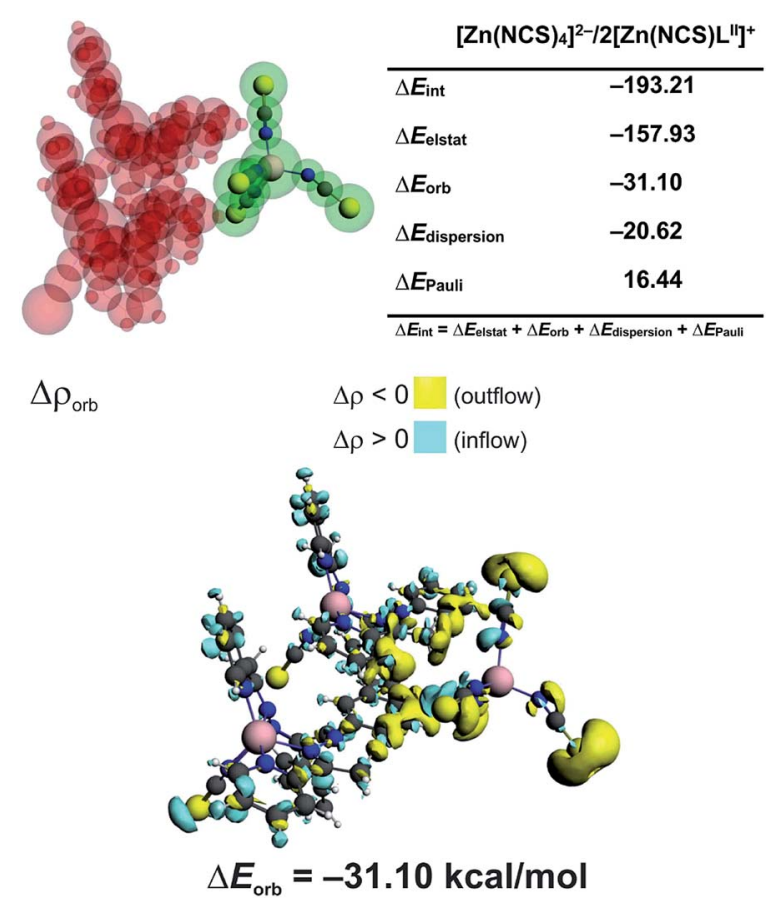

Fig. 5 (top) ETS-NOCV outcomes scrutinizing the nature of ionic interaction between $\left[\mathrm{Zn}(\mathrm{NCS})_{4}\right]^{2-}$ and two $\left[\mathrm{Zn}(\mathrm{NCS}) \mathrm{L}^{\mathrm{II}}\right]^{+}$in 3 . (bottom) The overall change in electron density $\Delta \rho_{\text {orb }}$ with the corresponding energy $\Delta E_{\text {orb }}$. 


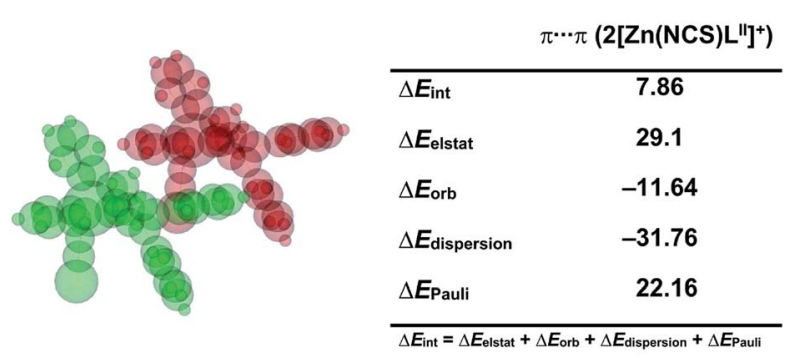

$\Delta \rho_{\text {orb }}$

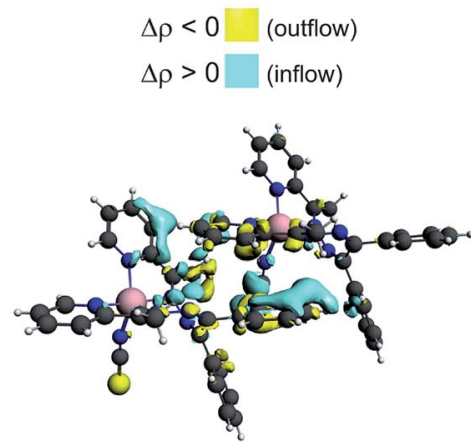

$$
\Delta E_{\text {orb }}=-11.64 \mathrm{kcal} / \mathrm{mol}
$$

Fig. 6 (top) ETS-NOCV outcomes scrutinizing the nature of ionic interaction between two $\pi$-stacked $\left[\mathrm{Zn}(\mathrm{NCS}) \mathrm{L}^{\mathrm{II}}\right]^{+}$units in 3. (bottom) The overall change in electron density $\Delta \rho_{\text {orb }}$ with the corresponding energy $\Delta E_{\text {orb }}$

we focus our attention on the characteristic seven-membered quasi-aromatic motif (7-MR), encompassing the twisted 1,1'(1,2-ethenediyl)bis-diazene (BDA) fragment and the metal atom (abbreviated as BDA-Zn). The BDA-based complexes with cadmium have recently been demonstrated to exhibit a unique type of transition-metal induced Möbius-like aromaticity in which the metal d-orbitals themselves do not contribute to the $\pi$-conjugation occurring at BDA. ${ }^{24,27}$ Since the quantitative study of aromaticity/electron delocalization in large systems is very difficult in practice, we have decided to consider the simplified BDA-Zn models adopting the exact fragments geometries from crystals of 1-3 (Fig. 7). The calculated total EDDB contours and electron populations have been dissected (according to the orbital symmetry) to get the strict $\pi$-contributions to quasiaromaticity; natural atomic charges on the metal and the two closest nitrogen atoms have been added together with the average dihedral angles and the calculated electric dipole moments (EDM). It was found, that the number of $\pi$-electrons delocalized in the quasi-aromatic rings, particularly in $\mathbf{1}$ and $\mathbf{2}$ (on average $\sim 3.3|e|$ ), resembles pretty much the values found for the previously studied BDA-Cd complexes, despite different configurations of the phenyl units and applying other ligands. ${ }^{24,27}$ The most twisted 7-MR in 1 (containing the most bulky substituents) is at the same time the most stabilized by quasi-aromaticity $(3.44|e|$, i.e. $\sim 0.6|e|$ per a quasi-ring member, which is comparable to the corresponding value for pyrrole $\left.{ }^{60}\right)$. Interestingly, it is found for the first time, that the systematic increase of the $\mathrm{Zn}-\mathrm{N}$ bond polarization when going from 1 to 3 reveals a strict correlation between EDM (i.e. indirectly the

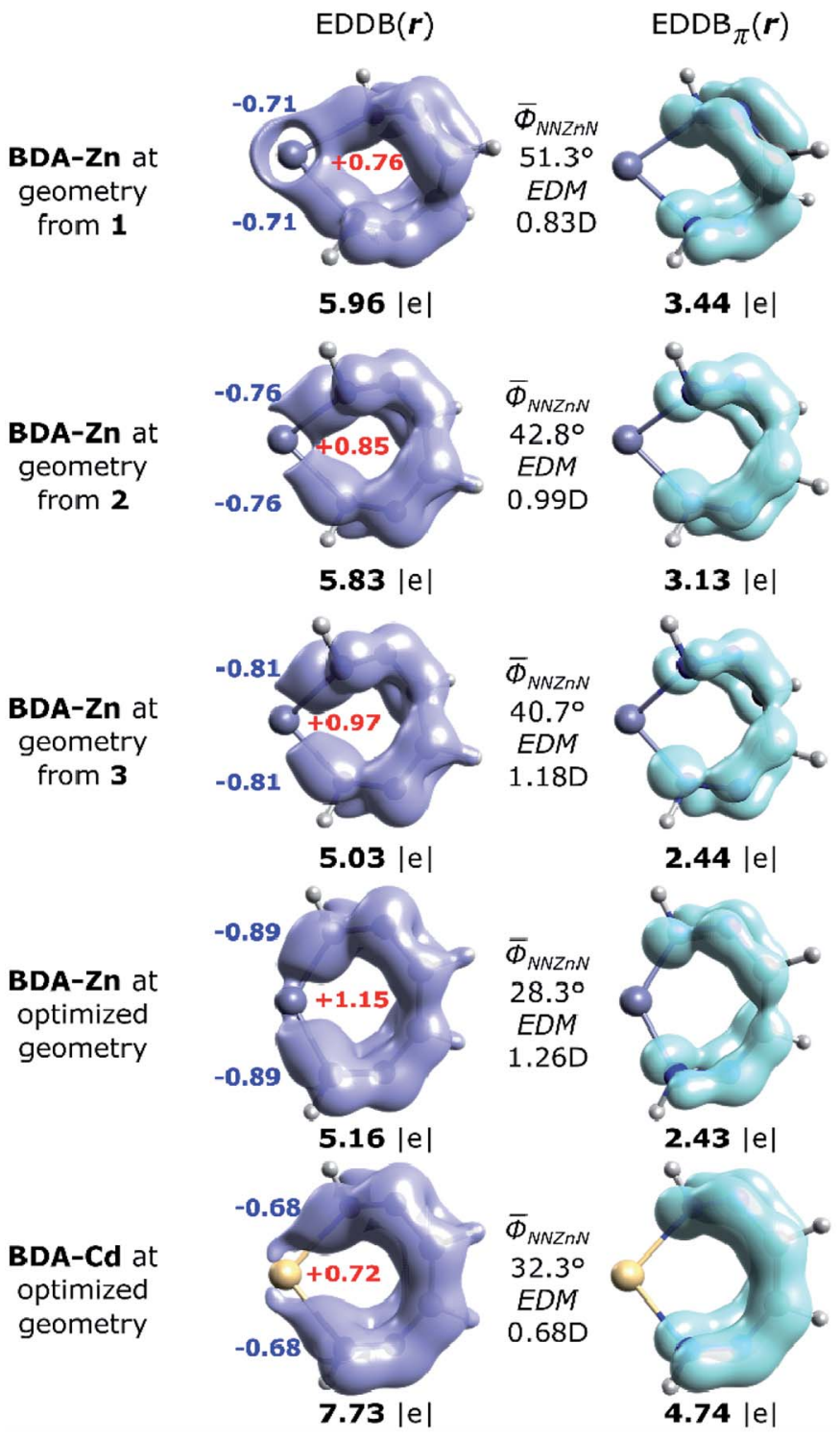

Fig. 7 Imagining of the $\operatorname{EDDB}(r)$ and $\operatorname{EDDB}_{\pi}(r)$ functions with the corresponding electron populations (in $|e|$ ) for the isolated 7-MR model systems at geometries adopted from the corresponding crystals of 1-3, as well as the fully optimized units: BDA-Zn and BDA-Cd. ${ }^{27}$ The natural atomic charges (colored bold numbers), average dihedral angles and the calculated electric dipole moments (EDM) have been added for comparison.

topology and the metal to BDA charge transfer) and $\pi$-electron delocalization: $R=-0.986$. In other words, the more twisted is the 7-MR, the more quasi-aromatic character is observed (Fig. 7). It demonstrates the two-folded role of bulky substituents: they are not only dispersion donors, ${ }^{40-56}$ but they also lead to amplification of the 7-MR twist (and enhanced quasiaromaticity). Previously only the former feature has been recognized. ${ }^{23-27}$ Interestingly, the optimized BDA-Zn structure (without steric effects from the $\mathrm{Ph}$ units) has significantly reduced quasi-aromaticity compared to 1 and $2(2.43|e|$, i.e. $\sim 0.4|e|$ per a quasi-ring member, which is comparable to the corresponding value for furan),$^{60}$ but at the same time, it is 
almost twice less aromatically-stabilized than its optimized BDA-Cd analogue $(4.74|e|$, i.e. $\sim 0.8|e|$ per a quasi-ring member, which is exactly between the corresponding values for pyrrole and benzene). ${ }^{60}$ Since both equilibrium structures have comparable average dihedral angles $\mathrm{N}-\mathrm{N}-\mathrm{M}-\mathrm{N}$, it is clearly the larger metal-nitrogen bond polarization (the charges $q_{\mathrm{Zn}}=$ $+1.15, q_{\mathrm{N}}=-0.9, \mathrm{EDM}=1.26 \mathrm{D}$ in BDA-Zn compared to $q_{\mathrm{Zn}}=$ $+0.72, q_{\mathrm{N}}=-0.7, \mathrm{EDM}=0.68 \mathrm{D}$ in BDA-Cd) that limits the $\pi$ electron delocalization in the 7-memberd quasi-aromatic unit (changes in the effectiveness of $\pi$-conjugation involving the $2 \mathrm{pz}$ orbitals of nitrogen atoms at close proximity of the metals are well marked in the $\operatorname{EDDB}_{\pi}(\mathrm{r})$ isocontours, Fig. 7). Such interrelation between the nature of metal-ligand bonding and quasi-aromaticity of the ligand has not been known before. ${ }^{23-27}$

\section{Conclusions}

In summary, we successfully isolated and characterized the quasi-aromatic Möbius type zinc complexes $\left[\mathrm{Zn}(\mathrm{NCS})_{2} \mathrm{~L}^{\mathrm{I}}\right](\mathbf{1})$, $\left[\mathrm{Zn}_{2}\left(\mu_{1,1}-\mathrm{N}_{3}\right)_{2}\left(\mathrm{~L}^{\mathrm{I}}\right)_{2}\right]\left[\mathrm{ZnCl}_{3}(\mathrm{MeOH})\right]_{2} \cdot 6 \mathrm{MeOH}$ (2) and $[\mathrm{Zn}(\mathrm{NCS})$ $\left.\mathrm{L}^{\mathrm{II}}\right]_{2}\left[\mathrm{Zn}(\mathrm{NCS})_{4}\right] \cdot \mathrm{MeOH}$ (3), fabricated from 1,2-diphenyl-1,2bis((phenyl(pyridin-2 yl)methylene)hydrazono)ethane $\left(\mathbf{L}^{\mathbf{I}}\right)$ or benzilbis(acetylpyridin-2-yl)methylidenehydrazone $\quad\left(\mathbf{L}^{\text {II }}\right)$, respectively, and $\mathrm{ZnCl}_{2}$ mixed with $\mathrm{NH}_{4} \mathrm{NCS}$ or $\mathrm{NaN}_{3}$. The creation of 1-3 is dictated by both the bulkiness of the organic ligand and the nature of inorganic counter ion.

Complex 1 has a neutral discrete heteroleptic mononuclear structure with the $\mathrm{Zn}^{\mathrm{II}}$ metal atom being chelated by one tetradentate ligand $\mathbf{L}^{\mathbf{I}}$ and two $\mathrm{N}$-bound $\mathrm{NCS}^{-}$anions with the formation of a distorted trigonal-prismatic $\mathrm{ZnN}_{6}$ coordination core. The $\left[\mathrm{Zn}(\mathrm{NCS})_{2} \mathrm{~L}^{\mathrm{I}}\right]$ monomers were found (due to the ETSNOCV calculations) to be bonded to each other primarily through London dispersion forces exerted by the presence of bulky hydrophobic substituents. Contrary, complexes 2 and 3 exhibit a salt-like structure where the long-range electrostatic forces were found to be of prime importance additionally to more typical non-covalent interactions $(\mathrm{O}-\mathrm{H} \cdots \mathrm{O}, \mathrm{C}-\mathrm{H} \cdots \mathrm{Cl}, \mathrm{C}-$ $\mathrm{H} \cdots \mathrm{S}, \mathrm{C}-\mathrm{H} \cdots \pi, \pi \cdots \pi)$. In 2 , the cation is a doubly charged centrosymmetric dinuclear structure with two $\mathrm{Zn}^{\mathrm{II}}$ atoms linked via two $\mu_{1,1}-\mathrm{N}_{3}^{-}$anions. Each metal center is further linked by the tetracoordinate ligand $\mathbf{L}$. The anionic part has a discrete mononuclear composition $\left[\mathbf{Z n C l}_{\mathbf{3}}(\mathbf{M e O H})\right]^{-}$. Notably, the anionic part of 2 together with the lattice $\mathrm{MeOH}$ molecules produces a synthon of motif $R_{8}^{8}(20)$ stabilized mostly by O-H $\cdots \mathrm{O}$ and $\mathrm{C}-\mathrm{H} \cdots \mathrm{Cl}$ interactions. Complex 3 is composed from two $\left[\mathbf{Z n}(\mathbf{N C S}) \mathbf{L}^{\mathrm{II}}\right]^{+}$cations with the $\mathrm{Zn}^{\mathrm{II}}$ atoms each being chelated by two pyridyl-imine fragments of $\mathbf{L}^{\text {II }}$ and further bound by one Nlinked $\mathrm{NCS}^{-}$anion. The anionic part of $\mathbf{3}$ is a doubly charged $\left[\mathrm{Zn}(\mathrm{NCS})_{4}\right]^{2-}$ species. Long range electrostatic forces between $\left[\mathbf{Z n}(\mathbf{N C S})_{4}\right]^{2-}$ and $\left[\mathbf{Z n}(\mathbf{N C S}) \mathbf{L}^{\mathbf{I I}}\right]^{+}$are responsible for the stability of 3 since pure $\pi \cdots \pi$ stacking between the $\left[\mathbf{Z n}(\mathbf{N C S}) \mathbf{L}^{\mathbf{I I}}\right]^{+}$units appeared to be repulsive. Finally, we have proven, by means of the $\mathrm{EDDB}^{57-61}$ study, that the seven-membered rings in 1-3 constitute a quasi-aromatic Möbius-type motif, though the absolute magnitude of such $\pi$-delocalization is notably weaker than in the corresponding cadmium-based analogs. ${ }^{24,27}$ Bulkiness of the ligands (L) are found not only to amplify London dispersion stabilization, ${ }^{24,27,40-56}$ but also influence the magnitude of quasi- $\pi$-delocalization (of Möbius-type) through modification of the polarity of $\mathrm{Zn}-\mathrm{L}$ bonding.

\section{Experimental}

\section{Materials}

All chemicals and solvents were used from commercial sources without further purification. $\mathbf{L}^{\mathbf{I}}$ and $\mathbf{L}^{\mathbf{I I}}$ were synthesized according to a literature method. ${ }^{20}$

\section{Physical measurements}

FTIR spectra were recorded on a Bruker Tensor 27 FTIR spectrometer. Microanalyses were performed using a ElementarVario EL III analyzer.

\section{Synthesis}

$\mathrm{ZnCl}_{2}(0.068 \mathrm{~g}, 0.5 \mathrm{mmol}), \mathrm{NH}_{4} \mathrm{NCS}(0.076 \mathrm{~g}, 1 \mathrm{mmol})$ or $\mathrm{NaN}_{3}$ $(0.065 \mathrm{~g}, 1 \mathrm{mmol})$ and $\mathbf{L}^{\mathbf{I}}$ or $\mathbf{L}^{\mathbf{I I}}(0.284$ and $0.222 \mathrm{~g}$, respectively; $0.5 \mathrm{mmol}$ ) were placed in the main arm of a branched tube. $\mathrm{MeOH}(15 \mathrm{~mL})$ was carefully added to fill the arms. The tube was sealed and immersed in an oil bath at $60{ }^{\circ} \mathrm{C}$ while the branched arm was kept at ambient temperature. X-ray suitable crystals were formed during the next days in the cooler arm and were filtered off.

(1) Colorless block-like crystals. Yield: $0.248 \mathrm{~g}$ (66\%). Anal. calc. for $\mathrm{C}_{40} \mathrm{H}_{28} \mathrm{~N}_{8} \mathrm{~S}_{2} \mathrm{Zn}$ (750.22) (\%): $\mathrm{C} 60.04, \mathrm{H} 3.76$ and $\mathrm{N}$ 14.94; found: C 60.29, H 3.83 and N 14.77.

(2) Yellow block-like crystals. Yield: $0.156 \mathrm{~g}$ (64\%). Anal. calc. for $\mathrm{C}_{84} \mathrm{H}_{88} \mathrm{Cl}_{6} \mathrm{~N}_{18} \mathrm{O}_{8} \mathrm{Zn}_{4}$ (1951.98) (\%): $\mathrm{C} 51.69, \mathrm{H} 4.54$ and $\mathrm{N}$ 12.92; found: $\mathrm{C}$ 51.56, $\mathrm{H} 4.61$ and $\mathrm{N} 12.81$.

(3) Yellow prism-like crystals. Yield: $0.174 \mathrm{~g}(73 \%)$. Anal. calc. for $\mathrm{C}_{63} \mathrm{H}_{52} \mathrm{~N}_{18} \mathrm{OS}_{6} \mathrm{Zn}_{3}$ (1465.74) (\%): C 51.62, H 3.58 and N 17.20; found: C 51.76, $\mathrm{H} 3.48$ and $\mathrm{N} 17.33$.

\section{ETS-NOCV charge and energy decomposition method}

The Natural Orbitals for Chemical Valence (NOCV) $\psi_{\mathrm{i}}$ constitute the canonical representation for a differential density matrix $\Delta P$ (it is formed by subtracting the appropriate molecular fragments density matrices from a density matrix of a molecule under consideration) in which $\Delta P$ adopts a diagonal form. It gives rise to the corresponding eigenvalues $v_{\mathrm{i}}$ and the related vectors $\psi_{\mathrm{i}}$. NOCVs occur in pairs $\left(\psi_{-k}, \psi_{k}\right)$ related to $\left|v_{k}\right|$ and they decompose overall deformation density $\Delta \rho$ into bonding components with different symmetries $\left(\Delta \rho_{k}\right)$ :

$$
\Delta \rho(r)=\sum_{k-1}^{M / 2} v_{k}\left[-\psi_{-k}^{2}+\psi_{k}^{2}(r)\right]=\sum_{k-1}^{M / 2} \Delta \rho_{k}(r)
$$

Usually, a few $k$ allow to recover a major shape of $\Delta \rho$. By combining NOCVs with ETS scheme in ETS-NOCV, one can obtain the related energetics, $\Delta E_{\text {orb }}(k)$, in addition to qualitative picture emerging from $\Delta \rho_{k}$. ETS originally divides the total bonding energy, between fragments, $\Delta E_{\text {total }}$, into four distinct components: $\Delta E_{\text {total }}=\Delta E_{\text {elstat }}+\Delta E_{\text {Pauli }}+\Delta E_{\text {orb }}+\Delta E_{\text {dispersion }}$. 
The $\Delta E_{\text {elstat }}$ is an energy of quasi-classical electrostatic interaction between fragments. The next term, $\Delta E_{\text {Pauli }}$, is responsible for repulsive Pauli interaction between occupied orbitals on the two fragments. The third component, $\Delta E_{\text {orb }}$, is stabilizing and shows formation of a chemical bond (including polarizations). In the ETS-NOCV scheme $\Delta E_{\text {orb }}$ is expressed in terms of the eigenvalues $v_{k}$ and diagonal Fock energy matrix elements $F_{\mathrm{i}, \mathrm{i}}^{\mathrm{TS}}$ (transformed into NOCV representation) as:

$$
\Delta E_{\mathrm{arb}}=\sum_{k} \Delta E_{\mathrm{arb}}(k)=\sum_{k-1}^{M / 2} v_{k}\left[-F_{-k,-k}^{\mathrm{TS}}+F_{k, k}^{\mathrm{TS}}\right]
$$

Finally, $\Delta E_{\text {dispersion }}$ denotes the semiempirical Grimme dispersion correction (D3).

\section{Single-crystal X-ray diffraction}

The X-ray data were collected on a Bruker APEX-II CCD single crystal diffractometer using graphite-monochromated Mo-K $\alpha$ radiation $(\lambda=0.71073 \AA)$. The collected frames were integrated with the Saint ${ }^{64}$ software using a narrow-frame algorithm. Data were corrected for absorption effects using the multi-scan method in SADABS. ${ }^{65}$ The space groups were assigned using XPREP of the Bruker ShelXTL ${ }^{66}$ package, solved with ShelXT ${ }^{66}$ and refined with ShelXL ${ }^{66}$ and the graphical interface ShelXle. ${ }^{67}$ All non-hydrogen atoms were refined anisotropically. Hydrogen atoms attached to carbon were positioned geometrically and constrained to ride on their parent atoms. Figures were generated using the program Mercury. ${ }^{68}$

Crystal data for 1. $\mathrm{C}_{40} \mathrm{H}_{28} \mathrm{~N}_{8} \mathrm{~S}_{2} \mathrm{Zn}, M_{\mathrm{r}}=750.19 \mathrm{~g} \mathrm{~mol}^{-1}, T=$ 296(2) K, monoclinic, space group $P 2_{1} / n, a=12.8146(10), b=$ 20.5355(17), $c=13.4451(11) \AA, \beta=98.225(1)^{\circ}, V=3501.7(5) \AA^{3}$, $Z=4, \rho=1.423 \mathrm{~g} \mathrm{~cm}^{-3}, \mu(\mathrm{Mo}-\mathrm{K} \alpha)=0.863 \mathrm{~mm}^{-1}$, reflections: 5447 collected, 5447 unique, $R_{\text {int }}=0.034, R_{1}$ (all) $=0.0363$, $\mathrm{w} R_{2}$ (all) $=0.0588, S=1.026$.

Crystal data for 2. $\mathrm{C}_{76} \mathrm{H}_{56} \mathrm{~N}_{18} \mathrm{Zn}_{2}, \mathrm{C}_{2} \mathrm{H}_{8} \mathrm{Cl}_{6} \mathrm{O}_{2} \mathrm{Zn}_{2}, 6\left(\mathrm{CH}_{4} \mathrm{O}\right) ; M_{\mathrm{r}}$ $=1951.9 \mathrm{~g} \mathrm{~mol}^{-1}, T=125(2) \mathrm{K}$, triclinic, space group $P \overline{1}, a=$ 11.836(4), $b=14.385(4), c=14.807(4) \AA, \alpha=68.045(3), \beta=$ 83.861(3), $\gamma=78.264(3)^{\circ}, V=2288.0(12) \AA^{3}, Z=2, \rho=$ $1.417 \mathrm{~g} \mathrm{~cm}^{-3}, \mu(\mathrm{Mo}-\mathrm{K} \alpha)=1.274 \mathrm{~mm}^{-1}$, reflections: 15639 collected, 5424 unique, $R_{\mathrm{int}}=0.053, R_{1}($ all $)=0.0648, \mathrm{w} R_{2}($ all $)=$ $0.1386, S=1.092$.

Crystal data for 3. $2\left(\mathrm{C}_{29} \mathrm{H}_{24} \mathrm{~N}_{7} \mathrm{SZn}\right), \mathrm{C}_{4} \mathrm{~N}_{4} \mathrm{~S}_{4} \mathrm{Zn}, \mathrm{CO} ; M_{\mathrm{r}}=$ $1461.66 \mathrm{~g} \mathrm{~mol}^{-1}, T=100(2) \mathrm{K}$, triclinic, space group $P \overline{1}, a=$ 13.3235(9), $b=15.6906(10), c=18.6880(13) \AA, \alpha=65.795(2)$, $\beta=71.872(2), \gamma=77.010(2)^{\circ}, V=3365.1(4) \AA^{3}, Z=2, \rho=$ $1.443 \mathrm{~g} \mathrm{~cm}^{-3}, \mu($ Mo-K $\alpha)=1.302 \mathrm{~mm}^{-1}$, reflections: 45317 collected, 15733 unique, $R_{\mathrm{int}}=0.060, R_{1}($ all $)=0.1102$, w $R_{2}($ all $)$ $=0.1712, S=1.024$.

\section{Contributions}

Mariusz P. Mitoraj has planned and partially performed (ETSNOCV) the theoretical calculations, written the manuscript text and analyzed the entire data. Farhad Akbari Afkhami has primarily done the experimental part. Ghodrat Mahmaoudi has planned the experimental research. Ali Akbar Khandar has supported the work, whereas Atash V. Gurbanov has synthesized the compounds. Fedor I. Zubkov has also participated in the synthesis of the compounds. Rory Waterman is a crystallographer of compound 1-2, whereas Himanshu Sekhar Jena is a crystallographer of system 3. D W. Szczepanik has done the aromaticity calculations. Damir A. Safin and Maria G. Babashkina have analysed and discussed the results as well as have written the manuscript.

\section{Conflicts of interest}

There are no conflicts to declare.

\section{Acknowledgements}

We are grateful to the University of Maragheh for the financial support of this research. We also thank "RUDN University Program 5-100" for the support. This work was also partially supported by the National Science Centre, Poland (grant no. 2015/17/D/ST4/00558, D. W. S.). M. P. M. acknowledges the financial support of the Polish National Science Center within the Sonata Bis Project 2017/26/E/ST4/00104. X-ray facilities were provided by the U. S. National Science Foundation (CHE1039436 to RW). H. S. J. thanks FWO [PEGASUS]2 Marie Sklodowska-Curie grant agreement no. 665501 for Incoming postdoctoral fellowship. D. W. S. acknowledges the European Union's Framework Programme for Research and Innovation Horizon 2020 (2014-2020) under the Marie Skłodowska-Curie Grant Agreement No. 797335 "MulArEffect”.

\section{References}

1 V. G. Machado, P. N. W. Baxter and J.-M. Lehn, J. Braz. Chem. Soc., 2001, 12, 431-462.

2 J. D. Watson and F. H. C. Crick, Nature, 1953, 171, 737-738.

3 J. Anastassopoulou and T. Theophanides, The Role of Metal Ions in Biological Systems and Medicine in Bioinorganic Chemistry. NATO ASI Series (Series C: Mathematical and Physical Sciences), Springer, Dordrecht, 1995, vol. 459, pp. 209-218.

4 F. A. Cotton, G. Wilkinson, C. A. Murillo and M. Bochmann, Advanced Inorganic Chemistry, John Wiley and sons, New York, 6th edn, 1999.

5 G. Struckmeier, U. Thewalt and J.-H. Fuhrhop, J. Am. Chem. Soc., 1976, 98, 278-279.

6 C. Piguet, G. Bernardinelli and G. Hopfgartner, Chem. Rev., 1997, 97, 2005-2062.

7 M. Albrecht, Chem. Rev., 2001, 101, 3457-3498.

8 M. G. B. Drew, D. Parui, S. De, J. P. Naskar and D. Datta, Eur. J. Inorg. Chem., 2006, 4026-4028.

9 T. Riss-Johannessen, L. P. Harding, J. C. Jeffery, R. Moon and R. C. Rice, Dalton Trans., 2007, 1577-1587.

10 Y. Wang, H. Fu, F. Shen, X. Sheng, A. Peng, Z. Gu, H. Ma, J. S. Ma and J. Yao, Inorg. Chem., 2007, 46, 3548-3556.

11 A. M. Stadler, N. Kyritsakas, G. Vanghan and J.-M. Lehn, Chem.-Eur. J., 2007, 13, 59-68. 
12 M. G. B. Drew, S. De and D. Datta, Inorg. Chim. Acta, 2009, 362, 2487-2491.

13 T. Kaczorowski, I. Justyniak, T. Lipińska, J. Lipkowski and J. Lewiński, J. Am. Chem. Soc., 2009, 131, 5393-5395.

14 S. De, M. G. B. Drew and D. Datta, Inorg. Chim. Acta, 2010, 363, 4123-4126.

15 C. S. Tsang, C. C. Yee, S. M. Yiu, W. T. Wong and H. L. Kwong, Polyhedron, 2014, 83, 167-177.

16 M. Enamullah, M. A. Quddus, M. R. Hasan, G. Pescitelli, R. Berardozzi, G. Makhloufi, V. Vasylyeva and C. Janiak, Dalton Trans., 2016, 45, 667-680.

17 M. Hasegawa, H. Ohtsu, D. Kodama, T. Kasai, S. Sakurai, A. Ishiia and K. Suzuki, New J. Chem., 2014, 23, 1225-1234.

18 S. Chowdhury, M. G. B. Drew and D. Datta, New J. Chem., 2003, 27, 831-835.

19 Q. Sun, Y. Bai, G. He, C. Duan, Z. Lin and Q. Meng, Chem. Commun., 2006, 2777-2779.

20 M. G. B. Drew, D. Parui, S. De, S. Chowdhury and D. Datta, New J. Chem., 2007, 31, 1763-1768.

21 G. Mahmoudi, V. Stilinović, M. S. Gargari, A. Bauzá, G. Zaragoza, W. Kaminsky, V. Lynch, D. ChoquesilloLazarte, K. Sivakumar, A. A. Khandar and A. Frontera, CrystEngComm, 2015, 17, 3493-3502.

22 A. Masoumi, M. S. Gargari, G. Mahmoudi, B. Machura, V. Lynch, G. Giester, M. Abedi and P. Hazendonk, Z. Anorg. Allg. Chem., 2015, 641, 1176-1181.

23 F. A. Afkhami, G. Mahmoudi, A. V. Gurbanov, F. I. Zubkov, F. Qu, A. Gupta and D. A. Safin, Dalton Trans., 2017, 46, 14888-14896.

24 G. Mahmoudi, F. A. Afkhami, A. Castiñeiras, I. GarcíaSantos, A. Gurbanov, F. I. Zubkov, M. P. Mitoraj, M. Kukułka, F. Sagan, D. W. Szczepanik, I. A. Konyaeva and D. A. Safin, Inorg. Chem., 2018, 57, 4395-4408.

25 F. A. Afkhami, G. Mahmoudi, J. M. White, J. Lipkowski, I. A. Konyaeva and D. A. Safin, Inorg. Chim. Acta, 2019, 484, 481-490.

26 F. A. Afkhami, G. Mahmoudi, A. A. Khandar, J. M. White, I. A. Konyaeva and D. A. Safin, J. Mol. Struct., 2019, 1176, 743-750.

27 M. P. Mitoraj, G. Mahmoudi, F. Afkhami, A. Castineiras, G. Giester, I. A. Konyaeva, A. A. Khandar, F. Qu, A. Gupta, F. Sagan, D. W. Szczepanik and D. A. Safin, Cryst. Growth Des., 2019, 19, 1649-1659.

28 H. Zhang, X. M. Wang, K. C. Zhang and B. K. Teo, Coord. Chem. Rev., 1999, 183, 157-195.

29 W. P. Fehlhammer and W. Z. Beck, Z. Anorg. Allg. Chem., 2013, 639, 1053-1082.

30 K. Nakamoto, Infrared and Raman Spectra of Inorganic and Coordination Compounds, Part B, Wiley, N. Y., 5th edn, 1997, p. 116.

31 G. Mahmoudi, J. K. Zaręba, A. V. Gurbanov, A. Bauzá, F. I. Zubkov, M. Kubicki, V. Stilinović, V. Kinzhybalo and A. Frontera, Eur. J. Inorg. Chem., 2017, 4763-4772.

32 http://www.ee.ub.edu/index.php? option=com_content\&view $=$ article\&id $=72 \&$ Itemid $=469$.

33 S. Alvarez, D. Avnir, M. Llunell and M. Pinsky, New J. Chem., 2002, 26, 996-1009.
34 L. Yang, D. R. Powell and R. P. Houser, Dalton Trans., 2007, 955-964.

35 J. Cirera, P. Alemany and S. Alvarez, Chem.-Eur. J., 2004, 10, 190-207.

36 S. Alvarez and M. Llunell, J. Chem. Soc., Dalton Trans., 2000, 3288-3303.

37 M. P. Mitoraj, A. Michalak and T. Ziegler, J. Chem. Theory Comput., 2009, 5, 962-975.

38 E. J. Baerends, J. Autschbach, D. Bashford, A. Bérces, F. M. Bickelhaupt, C. Bo, P. M. Boerrigter, L. Cavallo, D. P. Chong, L. Deng, R. M. Dickson, D. E. Ellis, M. van Faassen, L. Fan, T. H. Fischer, C. Fonseca Guerra, A. Ghysels, A. Giammona, S. J. A. van Gisbergen, A. W. Götz, J. A. Groeneveld, O. V. Gritsenko, M. Grüning, F. E. Harris, P. van den Hoek, C. R. Jacob, H. Jacobsen, L. Jensen, G. van Kessel, F. Kootstra, M. V. Krykunov, E. van Lenthe, D. A. McCormack, A. Michalak, M. Mitoraj, J. Neugebauer, V. P. Nicu, L. Noodleman, V. P. Osinga, S. Patchkovskii, P. H. T. Philipsen, D. Post, C. C. Pye, W. Ravenek, J. I. Rodríguez, P. Ros, P. R. T. Schipper, G. Schreckenbach, M. Seth, J. G. Snijders, M. Solà, M. Swart, D. Swerhone, G. te Velde, P. Vernooijs, L. Versluis, L. Visscher, O. Visser, F. Wang, T. A. Wesolowski, E. M. van Wezenbeek, G. Wiesenekker, S. K. Wolff, T. K. Woo, A. L. Yakovlev and T. Ziegler, ADF2012.01, Theoretical Chemistry, Vrije Universiteit, Amsterdamsoft.

39 O. A. Stasyuk, R. Sedlak, C. Fonseca Guerra and P. Hobza, J. Chem. Theory Comput., 2018, 14, 3440-3450.

40 I. Cukrowski, K. K. Govender, M. P. Mitoraj and M. Srebro, J. Phys. Chem. A, 2011, 115, 12746-12757.

41 I. Cukrowski, J. H. de Lange and M. P. Mitoraj, J. Phys. Chem. A, 2014, 118, 623-637.

42 J. P. Wagner and P. R. Schreiner, Angew. Chem., Int. Ed., 2015, 54, 12274-12296.

43 F. Sagan, Ł. Piękoś, M. Andrzejak and M. P. Mitoraj, Chem.Eur. J., 2015, 21, 15299-15307.

44 D. A. Safin, M. G. Babashkina, K. Robeyns, M. P. Mitoraj, P. Kubisiak and Y. Garcia, Chem.-Eur. J., 2015, 21, 1667916687.

45 F. Sagan, R. Filas and M. P. Mitoraj, Crystals, 2016, 6, 28.

46 I. Cukrowski, F. Sagan and M. P. Mitoraj, J. Comput. Chem., 2016, 37, 2783-2798.

47 D. J. Liptrot and P. P. Power, Nat. Rev. Chem., 2017, 1, 0004. 48 G. Bistoni, A. A. Auer and F. Neese, Chem.-Eur. J., 2017, 23, 865-873.

49 Q. Lu, F. Neese and G. Bistoni, Angew. Chem., Int. Ed., 2018, 57, 4760-4764.

50 M. P. Mitoraj, M. G. Babashkina, A. Y. Isaev, Y. M. Chichigina, K. Robeyns, Y. Garcia and D. A. Safin, Cryst. Growth Des., 2018, 18, 5385-5397.

51 P. M. Nowak, K. Olesek, M. Woźniakiewicz, M. Mitoraj, F. Sagan and P. Kościelniak, J. Chromatogr. A, 2018, 1580, 142-151.

52 G. Mahmoudi, E. Zangrando, M. P. Mitoraj, A. V. Gurbanov, F. I. Zubkov, M. Moosavifar, I. A. Konyaeva, A. M. Kirillov and D. A. Safin, New J. Chem., 2018, 42, 4959-4971. 
53 M. P. Mitoraj, F. Sagan, M. G. Babashkina, A. Y. Isaev, Y. M. Chichigina and D. A. Safin, Eur. J. Org. Chem., 2019, 493-503.

54 M. P. Mitoraj, M. G. Babashkina, K. Robeyns, F. Sagan, D. W. Szczepanik, Y. V. Seredina, Y. Garcia and D. A. Safin, Organometallics, 2019, 38, 1973-1981.

55 F. Sagan and M. P. Mitoraj, J. Phys. Chem. A, 2019, 123, 46164622.

56 F. Sagan and M. P. Mitoraj, Non-covalent Interactions in Selected Transition Metal Complexes in Transition Metals in Coordination Environments, Springer, 2019.

57 D. W. Szczepanik, E. J. Zak, K. Dyduch and J. Mrozek, Chem. Phys. Lett., 2014, 593, 154-159.

58 D. W. Szczepanik, M. Andrzejak, K. Dyduch, E. J. Zak, M. Makowski, G. Mazur and J. Mrozek, Phys. Chem. Chem. Phys., 2014, 16, 20514-20523.

59 D. W. Szczepanik, Comput. Theor. Chem., 2016, 1080, 33-37. 60 D. W. Szczepanik, M. Andrzejak, J. Dominikowska, B. Pawełek, T. M. Krygowski, H. Szatylowicz and M. Solà, Phys. Chem. Chem. Phys., 2017, 19, 28970-28981.
61 D. W. Szczepanik and M. Solà, ChemistryOpen, 2019, 8, 219227.

62 R. Gershoni-Porannea and A. Stanger, Chem. Soc. Rev., 2015, 44, 6597-6615.

63 D. Geuenich, K. Hess, F. Köhler and R. Herges, Chem. Rev., 2005, 105, 3758-3772.

64 Bruker Saint Plus, Saint Plus 8.34A, Bruker AXS Inc., Madison, Wisconsin, USA, 2007.

65 Bruker, SADABS, TWINABS, SADABS 2012/1, Bruker AXS Inc., Madison, Wisconsin, USA, 2001.

66 G. M. Sheldrick, Acta Crystallogr., 2008, 64, 112-122.

67 C. B. Hübschle, G. M. Sheldrick and B. Dittrich, J. Appl. Crystallogr., 2011, 44, 1281-1284.

68 C. F. Macrae, I. J. Bruno, J. A. Chisholm, P. R. Edgington, P. McCabe, E. Pidcock, L. Rodriguez-Monge, R. Taylor, J. van de Streek and P. A. Wood, J. Appl. Crystallogr., 2008, 41, 466-470. 